\title{
$1 \quad$ CV chondrites: more than one parent body
}

2 J. Gattacceca ${ }^{1}$, L. Bonal ${ }^{2}$, C. Sonzogni ${ }^{1}$, J. Longerey $^{1}$.

3

$4 \quad{ }^{1}$ CNRS, Aix Marseille Univ, IRD, Coll France, INRAE, CEREGE, Aix-en-Provence, France

$5 \quad{ }^{2}$ Institut de Planétologie et d'Astrophysique de Grenoble, Université Grenoble Alpes, CNRS

6 CNES, 38000 Grenoble, France

7

8 Corresponding author: gattacceca@ cerege.fr

9

10

11 Abstract

12

$\mathrm{CV}$ chondrites are one of the most studied group of carbonaceous chondrites. Based on a number of mineralogical features, they have been divided into three sub-groups: $\mathrm{CV}_{\text {OxA }}$, $\mathrm{CV}_{\mathrm{OxB}}$, and $\mathrm{CV}_{\text {Red. }}$ These sub-groups are classically interpreted as coming from a single parent body, with a common protolith affected by significant parent body fluid-assisted metasomatism occurring at different temperatures and/or redox conditions. In this work, we studied a set of $53 \mathrm{CV}$ chondrites. We classified them into the three sub-groups, measured their apparent chondrule sizes and their matrix modal abundance. We measured the triple oxygen isotopic composition for 17 of them. The distributions of chondrule size and matrix abundances in $\mathrm{CV}_{\mathrm{OxA}}$ and $\mathrm{CV}_{\mathrm{OxB}}$ cannot be statistically distinguished. Conversely, $\mathrm{CV}_{\mathrm{Red}}$ and $\mathrm{CV}_{\mathrm{Ox}}$ have distinct distributions. These two robust and simple petrographic indicators combined with the previous knowledge of the peak metamorphic temperatures experienced by these meteorites show that $\mathrm{CV}_{\mathrm{Ox}}$ and $\mathrm{CV}_{\mathrm{Red}}$ originate from two distinct parent bodies. On the other hand, $\mathrm{CV}_{\mathrm{OxA}}$ and $\mathrm{CV}_{\mathrm{OxB}}$ likely originate from the same parent body, with $\mathrm{CV}_{\text {OxA }}$ representing deeper, more metamorphosed levels. For clarification of the chondrite 
classification scheme, in which one group should ultimately represent a single parent body, we propose to divide the $\mathrm{CV}$ group into two proper groups (and not subgroups as is the current scheme), keeping the names $\mathrm{CV}_{\text {Red }}$ and $\mathrm{CV}_{\text {Ox }}$. These two groups can be readily separated by estimating the average nickel content of their sulfides.

\section{Introduction}

Most meteorites come from the main asteroid belt. They are extracted from asteroids by impact under the form of meteoroids ( centimeter- to meter-sized objects), that orbit in the interplanetary space for typically a few Myr before colliding with the Earth (e.g., Eugster et al., 2006; Gravnik and Brown, 2018). The 60000 meteorites registered to date by the Meteoritical Society are classified into groups (e.g., Weisberg et al., 2006). The general idea behind grouping is that meteorites from a group derive from the same primary parent body (senso Greenwood et al. (2020), i.e., the source body from which the meteorite ultimately derived), in most cases an asteroid. This is strictly applicable to chondrites, the classification for achondrites being a little less coherent. For instance, meteorites originating from asteroid Vesta are separated into three groups (eucrites, diogenites, howardites) and meteorites originating from Mars are separated into several groups as well (shergottites, nakhlites, ...). However, even for chondrites, it is not established that all meteorites within a group come from a single parent body, although this would be the ultimate objective of the classification scheme. CM chondrites, for instance, have been proposed to come from multiple parent bodies (e.g., Lee et al. 2019), but there has been no success in separating them into coherent sub-groups originating from distinct parent bodies.

The current classification scheme contains 50 groups (Weisberg et al., 2006). In addition, there are a number of ungrouped meteorites that derive from parent bodies that are not represented by these groups. This number can be roughly estimated to be a maximum of 50 
distinct parent bodies for ungrouped iron meteorites, and a maximum of 50 for ungrouped chondrites, based on the Meteoritical Bulletin Database. The total number of asteroids represented in the global meteorite collection is thus about 150 at most. A similar estimate of 110 asteroids was reached based on consideration of oxygen isotopes (Greenwood et al., 2017). A more recent estimate, also based on consideration of oxygen isotopes, places the number of parent bodies between 95 and 148 (Greenwood et al., 2020). In this total, the number of chondrite parent bodies is estimated to be approximately 15 to 20 , with an additional 11 to 17 parent bodies to account for ungrouped chondrites (Greenwood et al., 2020). Whatever the exact number of parent bodies represented in the global meteorite collection, it is almost negligible compared to the number of asteroids in the main belt, over one million asteroids larger than $1 \mathrm{~km}$ (Burbine et al., 2002). This suggests at first sight that meteorites are not representative at all of the asteroid population. However, asteroids were formed as bodies $>\sim 35 \mathrm{~km}$ (Delbo et al., 2017). The smaller asteroids in the present-day asteroid belt belong to dynamical families and thus represent fragments of a small number (several dozens) of shattered planetesimals (Delbo et al., 2017). In addition to these fragments, the asteroid belt contains a small number (about a hundred) of pristine planetesimals with a diameter above $\sim 35 \mathrm{~km}$ (Delbo et al., 2017). Therefore, with about 150 groups, meteorites may provide a rather exhaustive sampling of the planetesimals (shattered and pristine) that are present today in the asteroid belt. This justifies paying particular care to the grouping of meteorites into groups that actually originate from distinct primary parent bodies, especially for chondrites that are distributed within only 15 groups. Deciphering the parent body history, in terms of accretion (timing and physico-chemical environment) and evolution (thermal metamorphism and possible differentiation, aqueous alteration, and shock histories), also requires that the classification scheme efficiently separates groups of meteorites that were formed on different parent bodies. 
$\mathrm{CV}$ chondrites are a fairly abundant type of carbonaceous chondrites with 525 meteorites registered by the Meteoritical Society to date $(21 \%$ of the total number of carbonaceous chondrites). They are classically interpreted as coming from a single parent body (e.g., Krot et al, 1995). They have been divided into reduced $\left(\mathrm{CV}_{\mathrm{Red}}\right)$ and oxidized $\left(\mathrm{CV}_{\mathrm{Ox}}\right)$ sub-groups, based on a number of mineralogical features, the Ni content of sulfides and the abundance of Fe,Ni metal (McSween, 1977). The oxidized sub-group has been further divided into Allende$\left(\mathrm{CV}_{\text {OxA }}\right)$ and Bali- $\left(\mathrm{CV}_{\text {OxB }}\right)$ like sub-groups, based on a combination of chemical and petrographic criteria (e.g., Krot et al., 1998; Bonal et al., 2020). Although an in-depth discussion of relations between $\mathrm{CK}$ and $\mathrm{CV}$ chondrites is beyond the scope of this paper, we note that it had also been proposed that CK chondrites may come from a more thermally metamorphosed (deeper) part of the same CV parent body based on compositional and oxygen isotope evidence (e.g., Wasson et al., 2013; Greenwood et al., 2010). On these bases, it was proposed to make $\mathrm{CK}$ chondrites a new sub-group of $\mathrm{CV}$ chondrites named $\mathrm{CV}_{\mathrm{OxK}}$ (Greenwood et al., 2010). However, this interpretation has been later challenged by the different magnetite composition (Dunn et al., 2016) and the different chromium isotopic composition between CV and CK (Yin and Sanborn, 2019).

The present-day paradigm is that all CV chondrites come from a single parent asteroid, with a common protolith affected by significant parent body fluid-assisted metasomatism occurring at different temperatures and/or redox conditions (Krot et al., 1995; Ganino and Libourel, 2017). In this work we will argue that although $\mathrm{CV}_{\text {OxA }}$ and $\mathrm{CV}_{\text {OxB }}$ are likely to originate from a single parent body, $\mathrm{CV}_{\mathrm{Ox}}$ and $\mathrm{CV}_{\mathrm{Red}}$ originate from two distinct parent bodies.

\section{Material and methods}


We investigated a suite of $53 \mathrm{CV}$ chondrites. The main dataset is composed of 30

101 meteorites (7 falls and 23 finds, mostly from Antarctica) whose thermal metamorphism and 102 aqueous alteration history, matrix abundances, modal metal abundances, and sub103 classification into $\mathrm{CV}_{\text {OxA }}, \mathrm{CV}_{\text {OxB }}$, and $\mathrm{CV}_{\text {Red }}$ have been characterized previously (Bonal et al., 104 2020). This dataset was completed by 23 meteorites from hot deserts, mostly from Northwest 105 Africa (NWA meteorites). For this new set of meteorites, we determined the sub-group (OxA,

$106 \mathrm{OxB}$ or Red) by combining proxies (mostly the average $\mathrm{Ni}$ content of sulfides, the $\mathrm{Fe}, \mathrm{Ni}$ 107 metal abundance, and magnetic parameters) that have been shown to allow for a clear separation of the three sub-groups (Bonal et al., 2020). We also estimated the modal abundance of fine-grained matrix. We then estimated the apparent chondrule diameters for all

11053 meteorites. For a subset of samples, we measured the bulk oxygen isotopic composition by

111 laser fluorination coupled with isotope-ratio mass spectrometry.

112 The chemical compositions of sulfides and Fe,Ni metal were determined using either a

113 Cameca SX100 electron microprobe at CAMPARIS facility (15 kV accelerating voltage,

$11410 \mathrm{nA}$ current), or a Hitachi S3000-N Scanning Electron Microscope equipped with a Bruker 115 X-ray Energy Dispersive Spectrometer at CEREGE. Both natural and synthetic standards 116 were used for calibration.

117 Magnetic susceptibility $(\chi)$ was measured at CEREGE, using a MFK1 apparatus from 118 Agico in an AC field of 200 A.m $^{-1}$ (peak field) and frequency $976 \mathrm{~Hz}$. For easiness, it is 119 expressed in the following as $\log \chi$, with $\chi$ in $10^{-9} \mathrm{~m}^{3} / \mathrm{kg}$.

120 Chondrule apparent diameters were determined from mosaic images obtained by reflected 121 and/or transmitted light microscopy on thin and/or thick polished sections using a Leica 122 DM2500P microscope. Intact chondrules were outlined manually. Igneous chondrule rims, 123 that are abundant in CV chondrites (Rubin, 1984), were included in the chondrule outline 124 since they are obviously a pre-accretionary feature. The chondrule outlines were processed 
using imageJ software and fitted with ellipses to extract chondrule apparent diameters. Most chondrules are not spheres but ellipsoids, giving an ellipse rather than a circle when observed in section. The maximum and minimum axes of the ellipses, noted $a$ and $b$, were determined to estimate the aspect ratio of the chondrule. Chondrule apparent diameter was computed as $\sqrt{a}$ ab, which is the diameter of the circle with equivalent surface to the observed chondrule.

This method is slightly different from the simple averaging of $a$ and $b$ that is used classically

131 in the literature (e.g., Nelson and Rubin, 2002) and provide systematically higher diameter estimates. However, the difference between the two methods is negligible (less than $1 \%$ for

133 the typical aspect ratios observed in CV chondrules), so our results can be safely compared 134 with literature data. Because chondrules are igneous fragments with almost no initial porosity, 135 their volume will not change upon deformation. Our method therefore provides a more 136 reliable estimate of the initial diameter of the initially spherical chondrules.

137 Modal metal abundances were determined by reflected light optical microscopy on 138 polished sections by point-counting using a x500 magnification and a step size of $100 \mu \mathrm{m}$.

139 The modal abundances of fine-grained matrix were determined by reflected and transmitted

140 light optical microscopy on polished and thin sections by point-counting using a x200 141 magnification and a step size of $100 \mu \mathrm{m}$. The $95 \%$ confidence intervals around the modal 142 abundances were computed after Howarth (1998).

143 Measurements of oxygen isotopic compositions of $1.5 \mathrm{mg}$ aliquots of bulk gently 144 powdered CV meteorites were carried out at the Stable Isotopes Laboratory of CEREGE 145 using laser fluorination coupled with isotope ratio mass spectrometry (IRMS) (see e.g., 146 Alexandre et al., 2006; Suavet et al., 2010 for more details about the analytical procedure). 147 The initial sample mass was $112 \mathrm{mg}$ on average to ensure that measured aliquot is 148 representative of the bulk meteorite. The three oxygen isotopic compositions were measured 149 with a dual-inlet mass spectrometer ThermoScientific Delta V plus. The oxygen isotope 
150

results are expressed in \%o versus the international reference standard $\mathrm{V}-\mathrm{SMOW}: \delta^{18} \mathrm{O}=$ $\left[\left({ }^{18} \mathrm{O} /{ }^{16} \mathrm{O}\right)_{\text {sample }} /\left({ }^{18} \mathrm{O} /{ }^{16} \mathrm{O}\right)_{\mathrm{V}-\mathrm{SMOW}}-1\right] \times 1000$ and $\delta^{17} \mathrm{O}=\left[\left({ }^{17} \mathrm{O} /{ }^{16} \mathrm{O}\right)_{\text {sample }} /\left({ }^{17} \mathrm{O} /{ }^{16} \mathrm{O}\right)_{\mathrm{V}-\mathrm{SMOW}}\right.$ $1] \times 1000$. The $\delta^{18} \mathrm{O}$ and $\delta^{17} \mathrm{O}$ values of the reference gas were calibrated with measurements of NBS28 standard $\left(\delta^{18} \mathrm{O}=9.60 \%\right.$, Gröning, 2004). The $\delta^{17} \mathrm{O}$ value of the NBS28 standard is taken as $\delta^{17} \mathrm{O}=4.992 \%$, to ensure $\Delta^{17} \mathrm{O}=0 \%$, where $\Delta^{17} \mathrm{O}=\delta^{17} \mathrm{O}-0.52 \times \delta^{18} \mathrm{O}$. The measurements were corrected on a daily basis using $1.5 \mathrm{mg}$ quartz internal laboratory standard "Boulangé" (Alexandre et al., 2006; Suavet et al., 2010). During the analyzing period, the analytical uncertainties derived from repeated measurement $(n=16)$ of this internal laboratory standard are $0.08 \%, 0.14 \%, 0.013 \%$ for $\delta^{17} \mathrm{O}, \delta^{18} \mathrm{O}$ and $\Delta^{17} \mathrm{O}$, respectively.

A number of datasets were compared using the Kolmogorov-Smirnov (K-S) statistical test for two populations performed using Holliday (2017). The K-S test is used to tests the null hypothesis that the two data sets are from the same distribution. It provides a $p$ value that must be compared to the a priori level of significance $(\alpha)$. If $p>\alpha$, the null hypothesis cannot be rejected. If $p<\alpha$, the null hypothesis is rejected. The significance level $\alpha$ has a specific meaning: it is the probably of rejecting the null hypothesis when it is true. $\alpha$ is classically set at 0.05 , and we use this value in this work.

\section{Results}

All meteorites could be readily classified into one of the three sub-groups $\left(\mathrm{Ox}_{\mathrm{A}}, \mathrm{Ox}_{\mathrm{B}}, \mathrm{Red}\right)$, based mostly on the $\mathrm{Ni}$ content in sulfides and their magnetic susceptibility (Table 1, Figure 1). Unlike for fresh Antarctic meteorites and falls, the modal metal abundance in hot desert meteorites is not a reliable proxy for the separation into the three subgroups because metal is extensively altered into oxides and oxyhydroxides through terrestrial weathering during the residence of the meteorites in hot deserts. Magnetic susceptibility remains 
nevertheless a reliable proxy to separate $\mathrm{CV}_{\text {OxA }}$ from $\mathrm{CV}_{\mathrm{OxB}}$. Indeed, although terrestrial

176 weathering of metal-bearing meteorites does result in a decrease of magnetic susceptibility

177 (e.g., Rochette et al., 2003), it does not affect magnetite which is the main ferromagnetic

178 mineral in $\mathrm{CV}_{\text {Ox. }}$. Therefore, the cut-off value at $\log \chi=3.9-4$ for separation of $\mathrm{CV}_{\text {OxA }}$ from

$179 \mathrm{CV}_{\mathrm{OxB}}$ remains valid. On the contrary, the susceptibility of hot desert $\mathrm{CV}_{\mathrm{Red}}$ is lower on

180 average than that measured for falls and Antarctic $\mathrm{CV}_{\mathrm{Red}}$, with $\log \chi=4.12 \pm 0.45(\mathrm{n}=10)$

181 against $4.36 \pm 0.22(\mathrm{n}=5)$ for Antarctic $\mathrm{CV}_{\mathrm{Red}}$ and $4.52 \pm 0.22(\mathrm{n}=3)$ for $\mathrm{CV}_{\mathrm{Red}}$ falls (Rochette

182 et al., 2008; Bonal et al,. 2020). But $\mathrm{CV}_{\mathrm{Red}}$ are easily distinguished from $\mathrm{CV}_{\mathrm{Ox}}$ based on the

183 average Ni content of sulfides.

184 The $23 \mathrm{CV} 3$ chondrites from hot deserts separate into $4 \mathrm{CV}_{\text {OxA }}, 9 \mathrm{CV}_{\text {OxB }}, 10 \mathrm{CV}_{\text {Red. }}$

185 Together with the 30 meteorites studied in Bonal et al. (2020), the dataset comprises 14

$186 \mathrm{CV}_{\text {OxA }}, 20 \mathrm{CV}_{\text {OxB }}, 19 \mathrm{CV}_{\text {Red. }}$. The number of $\mathrm{CV}_{\text {OxB }}$ goes down to 18 when considering the

187 pairing of Antarctic meteorites proposed by Bonal et al. (2020).

188 A total of 2806 chondrule apparent diameters were measured (Table 1). We did not attempt 189 any correction to calculate a true (3D) size distribution from the 2D apparent size because it 190 has been shown that many correction models yield erroneous values and should not be applied

191 to chondrule size distributions (Metzler, 2018). Average values for the three sub-groups are

192 given in Table 2. Although the chondrule diameters of all CV chondrites are usually pooled

193 together to indicate an approximate mean apparent diameter of $900 \mu \mathrm{m}$ (Friedrich 2015), our

194 data show that CV chondrites actually have an average diameter of $801 \mu \mathrm{m}(\mathrm{n}=2806)$.

195 Moreover, $\mathrm{CV}_{\mathrm{Red}}$ meteorites have, on average, larger chondrules than $\mathrm{CV}_{\mathrm{Ox}}$ meteorites

$196(860 \mu \mathrm{m}$ versus $768 \mu \mathrm{m})$. The size distributions of the sub-groups were compared using the

197 K-S test (Table 3, Figure 2). The hypothesis that the chondrule size distributions of $\mathrm{CV}_{\text {OxA }}$

198 and $\mathrm{CV}_{\mathrm{OxB}}$ are different cannot be rejected $(\mathrm{p}=0.056>\alpha=0.05)$, whereas the chondrule size

199 distributions of $\mathrm{CV}_{\mathrm{Red}}$ and $\mathrm{CV}_{\mathrm{Ox}}$ are different $\left(\mathrm{p}=6.78 \times 10^{-10}<\alpha=0.05\right)$. 
Matrix modal abundances are also different between $\mathrm{CV}_{\mathrm{Ox}}$ and $\mathrm{CV}_{\mathrm{Red}}$ meteorites with 201 average values 52.3 vol. $\%$ and 40.3 vol. \%, respectively (Table 2). Their distributions were compared using the K-S test (Table 3 ). With $\mathrm{p}=1.23 \times 10^{-4}$, the matrix abundance distributions of $\mathrm{CV}_{\mathrm{Red}}$ and $\mathrm{CV}_{\mathrm{Ox}}$ are different. Conversely, the distributions of matrix abundances in $\mathrm{CV}_{\mathrm{OxA}}$ and $\mathrm{CV}_{\text {OхB }}$ cannot be distinguished at the $5 \%$ significance level $(\mathrm{p}=0.295>\alpha=0.05)$.

Oxygen isotopes were measured in this study for $17 \mathrm{CV}$ chondrites (Table 4). Literature data are available for another $56 \mathrm{CV}$ chondrites (Table 5, Figure 3), but most of these chondrites are not subclassified into $\mathrm{CV}_{\text {Red }}$ and $\mathrm{CV}_{\text {Ox }}$. It has been noted earlier that $\mathrm{CV}$ chondrite can have heterogeneous oxygen isotopic composition (Greenwood et al., 2010). This is attributable to the small mass analyzed (usually in the mg range), combined with the size of their petrographic components: chondrules, calcium-aluminum inclusions (CAIs) and matrix lumps can be mm-sized and have widely variable oxygen isotopic composition (Clayton and Mayeda, 1999). In this study, we started from as large as possible bulk samples before analyzing a $1.5 \mathrm{mg}$ aliquot. To reduce this homogeneity issue, when multiple analyses 214 are available from the literature and our analyses, we use the average value (Table 5). 215 Combining our new data and literature data, oxygen isotopic composition is available for 7 $216 \mathrm{CV}_{\text {OxA }}, 10 \mathrm{CV}_{\text {OxB }}, 4 \mathrm{CV}_{\mathrm{Ox}}$, and $16 \mathrm{CV}_{\text {Red }}$. In a three-isotope plot, the data are distributed along a line with slope 0.94 (Clayton, 1993), called the carbonaceous chondrite anhydrous 218 mineral (CCAM) line. Therefore, the discussion can be limited to either $\delta^{18} \mathrm{O}$ or $\delta^{17} \mathrm{O}$. The 219 distributions of $\delta^{18} \mathrm{O}$ for the three sub-groups were tested using the K-S test. Again, the 220 hypothesis that $\mathrm{CV}_{\text {Red }}$ and $\mathrm{CV}_{\text {Ox }}$ have identical distributions can be rejected at the 5\% 221 significance level $\left(\mathrm{p}=6.0 \times 10^{-5}<\alpha=0.05\right)$, whereas $\mathrm{CV}_{\text {OxA }}$ and $\mathrm{CV}_{\text {OxB }}$ distribution cannot be 222 distinguished at the same significance level $(\mathrm{p}=0.117>\alpha=0.05)$. This latter observation 223 contradicts previous observations that $\mathrm{CV}_{\mathrm{OxB}}$ have a heavier oxygen isotopic than $\mathrm{CV}_{\text {OxA }}$ 224 (Clayton and Mayeda, 1999; Greenwood, 2010), which was interpreted as more extensive 
aqueous alteration in $\mathrm{CV}_{\text {OxB }}$ than in $\mathrm{CV}_{\text {OxA }}$. We attribute this discrepancy to the more limited 226 dataset used in previous studies.

\section{Discussion}

The distribution of matrix abundances and chondrule apparent diameters are identical for $\mathrm{CV}_{\mathrm{OxA}}$ and $\mathrm{CV}_{\mathrm{OxB}}$ chondrites but significantly different between $\mathrm{CV}_{\mathrm{Ox}}$ and $\mathrm{CV}_{\mathrm{Red}}$ chondrites.

Regarding chondrule apparent diameter, it is noteworthy that chondrules are usually not spherical but ellipsoidal. This flattening, also observed at microscopic scale (Bland et al., 2011) is likely due to hypervelocity impacts (e.g., Gattacceca et al., 2005). However, the larger apparent chondrule diameters of $\mathrm{CV}_{\mathrm{Red}}$ compared to $\mathrm{CV}_{\mathrm{Ox}}$ cannot be attributed to the effect of chondrule flattening. First, $\mathrm{CV}_{\mathrm{Red}}$ chondrules are only slightly more flattened than $\mathrm{CV}_{\mathrm{Ox}}$ chondrules, with average aspect ratio 1.33 and 1.27 , respectively (Table 2 ). Second, we estimated the effect of the flattening of spherical chondrules into oblate ellipsoids on the average apparent surface of the chondrules in polished sections (Supplementary figure S1).

This was done using an analytical solution for the intersection of plane and ellipsoids (Klein, 2012). The effect is a decrease of the apparent surface for increasing flattening. The effect is small (about $0.5 \%$ average apparent diameter decrease for an aspect ratio of 1.35), and more importantly it is the opposite of what is observed: $\mathrm{CV}_{\mathrm{Red}}$ are slightly more flattened on average than $\mathrm{CV}_{\mathrm{Ox}}$, but they have larger chondrules. The difference in chondrule size

244 distribution between $\mathrm{CV}_{\mathrm{Ox}}$ and $\mathrm{CV}_{\mathrm{Red}}$ is therefore a primary feature from the time of 245 accretion, and is not related to secondary parent body processes (shock).

246 Regarding matrix abundance, it is noteworthy than hypervelocity impacts will reduce 247 matrix porosity (e.g., Bland et al., 2011; Rubin, 2012) and reduce its modal abundance 248 compared to chondrules that have sub-null initial porosity. However, although it often 249 assumed that $\mathrm{CV}_{\text {Red }}$ are more shocked than $\mathrm{CV}_{\mathrm{Ox}}$ on average based on a very limited number 
of unusually shocked $\mathrm{CV}_{\text {Red }}$ (mostly Leoville and Efremovka), it has been shown recently that

251 this is not the case. Indeed, shock stages for $\mathrm{CV}_{\mathrm{Ox}}$ and $\mathrm{CV}_{\mathrm{Red}}$ have essentially the same 252 distribution (Bonal et al., 2020). This is confirmed here by the almost identical chondrule apparent aspect ratio for $\mathrm{CV}_{\mathrm{Red}}$ and $\mathrm{CV}_{\mathrm{Ox}}$ (Tables 1 and 2). Therefore, the difference in matrix abundance distribution between $\mathrm{CV}_{\mathrm{Ox}}$ and $\mathrm{CV}_{\text {Red }}$ is also a primary feature from the time of accretion.

These two robust petrographic indicators (chondrule size and matrix abundance) can be interpreted in two different ways: $\mathrm{CV}_{\mathrm{Ox}}$ and $\mathrm{CV}_{\text {Red }}$ originate from different stratigraphic position within a single parent body, or from two distinct parent bodies. Different stratigraphic positions in an asteroid with "onion-shell" structure would imply contrasted metamorphic temperatures with the deeper group being metamorphosed to higher temperatures. This is not observed, as both $\mathrm{CV}_{\mathrm{Ox}}$ and $\mathrm{CV}_{\mathrm{Red}}$ meteorites span the whole range of type 3 metamorphic subtypes (Bonal et al., 2020). Therefore, $\mathrm{CV}_{\mathrm{Ox}}$ and $\mathrm{CV}_{\mathrm{Red}}$ meteorites must originate from two different parent bodies. The existence of $\mathrm{CV}_{\mathrm{Ox}}$ clasts in Vigarano $\mathrm{CV}_{\text {Red }}$ regolith breccia (Krot et al., 2000), often used as an evidence for a single parent body 265 is not a decisive argument as xenolithic clasts from different meteorite groups are found in a 266 number of meteorites. About 5\% of impacts in the main asteroid belt should occur at 267 velocities that are below the estimated survivable impact velocity for stony meteorites (Bottke et al., 1994; Bland, 2001), so that chondritic xenoliths are expected in chondrites, especially

269 for chondrites from the same clan that are interpreted to come from parent bodies located at 270 similar heliocentric distances. For instance, several ordinary chondrites contain cm-size clasts 271 from another ordinary chondrite group (e.g., Gattacceca et al., 2017).

$272 \mathrm{CV}_{\mathrm{OxA}}$ and $\mathrm{CV}_{\mathrm{OxB}}$ cannot be distinguished in terms of chondrule size and matrix 273 abundance. As such they may well originate from the same parent body. It was recently 274 evidenced that $\mathrm{CV}_{\mathrm{OxA}}$ are systematically more metamorphosed than $\mathrm{CV}_{\mathrm{OxB}}$, with a continuum 
spanning all the petrographic subtypes 3.0 to $\geq 3.7$ (Bonal et al., 2020). Such a distribution of

276 metamorphic grades is very unlikely to be casual and strongly suggests that indeed, $\mathrm{CV}_{\mathrm{OxA}}$ 277 represent deeper level than $\mathrm{CV}_{\mathrm{OxB}}$ in a single and thermally stratified parent body. A potential 278 counter-argument is that experimental data show that dehydration by heating of a 279 phyllosilicate-bearing rock should result in a shift towards heavier oxygen isotopic 280 composition (Mayeda and Clayton, 1998). Such a trend is not seen in the oxygen isotopic 281 distributions of $\mathrm{CV}_{\mathrm{OxA}}$ and $\mathrm{CV}_{\mathrm{OxB}}$, that cannot be distinguished by the $\mathrm{K}-\mathrm{S}$ test. However, $282 \mathrm{CV}_{\mathrm{Ox}}$ chondrites are complex rocks with only a minor fraction of phyllosilicates, a few wt.\% at most (Bonal et al., 2020), so that the effect of dehydration of phyllosilicates during thermal metamorphism would not be significant compared to the natural inhomogeneity of oxygen isotopic composition of $\mathrm{CV}$ chondrites discussed above.

286 The difference between $\mathrm{CV}_{\mathrm{Red}}$ and $\mathrm{CV}_{\mathrm{Ox}}$ in terms of oxygen isotopic composition may be a 287 primary feature acquired at the time of accretion, or a secondary parent body feature. A parent 288 body origin can be tested by assuming an original identical oxygen isotopic composition later 289 modified by aqueous alteration and/or thermal metamorphism. We tested the correlation 290 between $\delta^{18} \mathrm{O}$ and quantitative proxies describing aqueous alteration and thermal 291 metamorphism (Figure 4). For aqueous alteration we use the total mass loss between 200 and 292 $900{ }^{\circ} \mathrm{C}$ during thermogravimetric analyses (TGA) that increases with increasing hydration of 293 the meteorite. For thermal metamorphism, we use the Raman spectral parameter $\mathrm{FWHM}_{\mathrm{D}}$ that 294 decreases with increasing peak metamorphic temperature. The TGA and Raman parameters 295 are from Bonal et al. (2020). We see no correlation between $\delta^{18} \mathrm{O}$ and TGA parameters $296\left(\mathrm{R}^{2}=0.007\right)$, suggesting no straightforward influence of aqueous alteration on the oxygen 297 isotopic composition of $\mathrm{CV}$ chondrites. There is a correlation between $\delta^{18} \mathrm{O}$ and the Raman 298 spectroscopy parameter $\mathrm{FWHM}_{\mathrm{D}}\left(\mathrm{R}^{2}=0.27\right.$, Figure 4). Such a correlation suggests that higher 299 metamorphic temperatures result in heavier oxygen isotope compositions. This can be 
accounted for by the effects of metamorphic heating, such as recrystallization or dehydration,

301 that would result in an increase of $\delta^{18} \mathrm{O}$ by mass fractionation. But the observed correlation is 302 faint $\left(\mathrm{R}^{2}=0.27\right)$, and it does not hold at all if we consider $\mathrm{CV}_{\mathrm{OxA}}$ and $\mathrm{CV}_{\mathrm{OxB}}$ subgroups.

303 Eventually, we find no robust correlation between the peak metamorphic temperature or the 304 degree of aqueous alteration, and the oxygen isotopic composition of CV chondrites: no 305 global parent body processes is able to account for the observed distribution of oxygen 306 isotopic compositions in $\mathrm{CV}_{\mathrm{Ox}}$ and $\mathrm{CV}_{\text {Red }}$ chondrites. Therefore, the difference in isotopic 307 composition between $\mathrm{CV}_{\mathrm{Red}}$ and $\mathrm{CV}_{\mathrm{Ox}}$ is more likely controlled by subtle differences in the abundances of petrographic components (matrix, chondrules, CAIs for instance), or by accretion at slightly different distances from the Sun implying reservoirs with slightly different oxygen isotopic compositions.

311 Cosmic ray exposure (CRE) ages, that represent the transit time of a meteorite (under the 312 form of a meteoroid) from the asteroid belt to the Earth are another useful proxy in the 313 discussion about whether different meteorites may originate from a single parent body. 314 Similar CRE ages may indicate provenance from the same parent body affected by a major 315 disruption event. However, the dataset of CRE ages for CV chondrites is limited to 4, 5, and 3 316 ages available for $\mathrm{CV}_{\text {OxA }}, \mathrm{CV}_{\text {OxB }}$ and $\mathrm{CV}_{\text {Red }}$, respectively (Schere and Schultz, 2000). The three sub-groups span broadly the same time interval of CRE ages between 1.7 and $28.1 \mathrm{Ma}$, 318 with average $\mathrm{CRE}$ ages $16.0 \pm 7.8 \mathrm{Ma}(\mathrm{n}=4)$ for $\mathrm{CV}_{\text {OxA }}, 11.0 \pm 9.4 \mathrm{Ma}(\mathrm{n}=5)$ for $\mathrm{CV}_{\text {OxB }}, 13.2$ $319 \pm 9.1 \mathrm{Ma}(\mathrm{n}=9)$ for all $\mathrm{CV}_{\mathrm{Ox}}$, and $8.6 \pm 2.2 \mathrm{Ma}(\mathrm{n}=3)$ for $\mathrm{CV}_{\text {Red. }}$. Because of the limited 320 dataset, CRE ages cannot be used to discuss the hypothesis of a single or multiple parent 321 bodies for CV chondrite sub-groups.

322 We have demonstrated that $\mathrm{CV}_{\text {Red }}$ and $\mathrm{CV}_{\text {Ox }}$ meteorites come from two distinct parent 323 bodies. Because the ultimate goal in chondrite classification is that a chondrite group 324 represents one parent body, $\mathrm{CV}_{\text {Red }}$ and $\mathrm{CV}_{\mathrm{Ox}}$ should be separated into two proper groups. 
325 Chondrite groups are classically, but not systematically, named after the first fall of the group.

326 Strictly speaking, the $\mathrm{CV}$ appellation, that comes from Vigarano $\mathrm{CV}_{\mathrm{Red}}$ fall, should be 327 applicable only to $\mathrm{CV}_{\text {Red }}$ chondrites, and an alternative name should be defined for $\mathrm{CV}_{\text {Ox }}$ 328 chondrites. Such a name could be CA for the iconic Allende meteorite, because all other $\mathrm{CV}_{\text {Ox }}$ 329 fall names (except Grosnaja) initiate with letters already in use for other meteorite groups. 330 However, because there are already thousands of scientific publications about Allende and 331 other $\mathrm{CV}_{O x}$ meteorites calling them $\mathrm{CV}$, it very likely that such an appellation would encounter strong resistance from the meteorite community. Therefore, the best names for these two separate meteorite groups are probably simply $\mathrm{CV}_{\mathrm{Ox}}$ and $\mathrm{CV}_{\mathrm{Red}}$, where the reference to Vigarano remain somewhat valid since this meteorite contains material from both associated parent bodies. We hope that from now on, $\mathrm{CV}$ chondrites will be required to be

336 declared to the Meteoritical Society as $\mathrm{CV}_{\mathrm{Ox}}$ or $\mathrm{CV}_{\mathrm{Red}}$, and not only as $\mathrm{CV}$. On the other hand, the distinction between $\mathrm{CV}_{\mathrm{OxA}}$ and $\mathrm{CV}_{\mathrm{OxB}}$ is only related to thermal metamorphic intensity 338 and could be overlooked in the classification scheme.

339 On a practical point of view, the easiest and most robust way to separate $\mathrm{CV}_{\mathrm{Red}}$ and $\mathrm{CV}_{\mathrm{Ox}}$ 340 is to estimate the average Ni content of sulfides. Indeed, in contrast to metal abundance or 341 magnetic parameters, this indicator is not much affected by terrestrial weathering. Analyses of 342 a random selection of about 10 to 20 sulfide grains is enough to decide between $\mathrm{CV}_{\text {Red }}$ and $343 \mathrm{CV}_{\mathrm{Ox}}$ and can be performed routinely during classification work using either an electron 344 microprobe or a scanning electron microscope equipped with an energy dispersive 345 spectrometer.

\section{Conclusions}

348 The comparison of chondrule size distribution, matrix abundances, metamorphic history 349 (and marginally oxygen isotopic composition) of the three sub-groups of CV chondrites 
350 indicate that $\mathrm{CV}_{\text {Red }}$ and $\mathrm{CV}_{\mathrm{Ox}}$ originate from distinct parent bodies. In view of the many

351 petrographic, compositional and isotopic similarities between $\mathrm{CV}_{\mathrm{Ox}}$ and $\mathrm{CV}_{\mathrm{Red}}$, these two 352 parent bodies may have however formed at roughly the same heliocentric distance and time.

353 On the other hand, $\mathrm{CV}_{\mathrm{OxA}}$ and $\mathrm{CV}_{\mathrm{OxB}}$ likely originate from the same parent body, with $354 \mathrm{CV}_{\text {OxA }}$ representing deeper, more metamorphosed levels of the original asteroid with onion355 shell structure. This new view must be considered in future works about the formation and 356 evolution of these two parent bodies, as results (existing and to come) must be interpreted in 357 two separate frameworks.

358 For clarification of the chondrite classification scheme, in which one group should 359 represent a parent body, we propose to break the CV group into two proper groups (and not 360 subgroups as is the current scheme), keeping the names $C V_{\text {Red }}$ and $C V_{\text {Ox }}$. These two groups 361 can be readily separated by estimating the average nickel content of their sulfides.

\section{Acknowledgements}

364 We thank two anonymous reviewers for their constructive comments. We thank Yoann 365 Quesnel for coding the computation of the effect of flattening on chondrule apparent 366 diameters. We thank Jeff Grossman for useful discussion about meteorite nomenclature.

\section{$368 \quad$ Figure captions}

369 Figure 1: Ni content of sulfides versus magnetic susceptibility for the CV chondrites studied 370 in this work. Light blue $=\mathrm{CV}_{\text {OxA }}$, deep blue $=\mathrm{CV}_{\text {OxB }}$, red $=\mathrm{CV}_{\text {Red. }}$ Circles are for hot desert 371 meteorites (this study), squares are for Antarctic meteorites and falls (Bonal et al., 2020).

373 Figure 2: Cumulative percentile plots for apparent chondrule size, matrix abundance and $374 \delta^{18}$ O. Light blue $=\mathrm{CV}_{\text {OxA }}$, deep blue $=\mathrm{CV}_{\text {OxB }}$, black $=\mathrm{CV}_{\text {Ox }}$, red $=\mathrm{CV}_{\text {Red }}$ 
376 Figure 3: Oxygen isotopic composition of CV chondrites. The CCAM line is from Clayton 377 (1993).

Figure 4: Oxygen isotopic composition versus (a) the total mass loss as measured by TGA 380 between 200 and $900{ }^{\circ} \mathrm{C}$, (b) the Raman spectral parameter $\mathrm{FWHM}_{\mathrm{D}}$. The TGA parameters 381 reflects the present-day hydration state of the samples, while the Raman parameters the experienced peak metamorphic temperature. Light blue $=\mathrm{CV}_{\text {OxA }}$, deep blue $=\mathrm{CV}_{\mathrm{OxB}}$, $\mathrm{red}=\mathrm{CV}_{\text {Red }}$.

Supplementary figure S1: Effect of flattening on the average apparent diameters of chondrules. This graph shows the ratio of the average equivalent diameters (i.e., diameter of the disk with equivalent surface) of the of the intersection of ellipsoids with planes of random orientation as a function of the aspect ratio of these ellipsoids. To simulate the case of chondrules flattening by impacts, the case considered here is for oblate ellipsoids that have identical long and intermediate axis. The initial diameter considered here for normalizing the ellipsoid diameter assumes volume conservation during flattening.

\section{Table captions}

394 Table 1. CV chondrites physical, petrological and geochemical properties

395 Metal abundance: $t r$ indicate that traces of metal have been observed. No polished section was 396 available for GRA 06101. References: R2008= Rochette et al. (2008), B2020 = Bonal et al. 397 (2020). 
401 Table 3: Kolmogorov-Smirnov test results.

$402 \mathrm{~N}$ is the number of meteorites in the considered population. The hypothesis that the two 403 distributions are identical can be rejected if $\mathrm{p}>\alpha$. If $\mathrm{p}<\alpha$, this hypothesis cannot be rejected. $404 \alpha$ is the significance level of the K-S test and is taken as 0.05 in this study.

405

Table 4: CV3 oxygen isotopic compositions measured in this study.

407

Table 5: summary of CV3 oxygen isotopic compositions. References: C\&M1999= Clayton and Mayeda, 1999; G2010= Greenwood, 2010; MDB= Meteoritical Society Meteorite

Database (https://www.lpi.usra.edu/meteor/).

\section{References}

Alexandre, A., Basile-Doelsch, I., Sonzogni, C., Sylvestre, F., Parron, C., Meunier, J.-D., Colin, F., 2006. Oxygen isotope analyses of fine silica grains using laser-extraction technique: Comparison with oxygen isotope data obtained from ion microprobe analyses and application to quartzite and silcrete cement investigation. Geochim. Cosmochim. Acta 70, 2827-2835.

Bland, P. A., 2001. Quantification of meteorite infall rates from accumulations in deserts, and meteorite accumulations on Mars. In Accretion of extraterrestrial matter throughout Earth's history, edited by Peucker-Ehrenbrink B. and Schmitz B. New York: Kluwer Academic/Plenum Publishers. pp. 267-303.

Bland, P.A., Howard, L.E., Prior, D.J., Wheeler, J., Hough, R.M., Dyl, K.A., 2011. Earliest rock fabric formed in the Solar System preserved in a chondrule rim. Nature Geoscience 
Bonal, L., Gattacceca, J., Garenne, A., Eschrig, J., Rochette, P., Krämer Ruggiu, L., 2020. Water and heat: new constraints on the evolution of the CV chondrite parent body. Geochim. Cosmochim. Acta, 276, 363-383.

Bottke, W. F. Jr., Nolan, M. C., Greenberg, R., Kolvoord, R. A., 1994. Velocity distributions among colliding asteroids. Icarus 107, 255-268.

Burbine, T.H., McCoy, T.J., Meibom, A., Gladman, B., Keil, K., 2002. Meteoriticparent bodies: their number and identification. In: Bottke, W.F., Cellino, A.,Paolicchi, P., Binzel, R.P. (Eds.), Asteroids III. University of Arizona Press, Tucson, pp. 653-667.

Clayton, R. N., 1993. Oxygen isotopes in meteorites. Ann. Rev. Earth Planet. Sci. 21, 115149.

Clayton, R.N., Mayeda, T.K., 1999. Oxygen isotope studies of carbonaceous chondrites. Geochim. Cosmochim. Acta 63, 2089-2104.

Delbo, M., Walsh, K., Avdellidou, C., Morbidelli, A., 2017. Identification of a primordial asteroid family constrains the original planetesimal population. Science 357, 10261029.

Dunn, T. L., Gross, J., Ivanova, M. A., Runyon, S. E., Bruck, A. M., 2016. Magnetite in the unequilibrated CK chondrites: Implications for metamorphism and new insights into the relationship between the CV and CK chondrites. Meteoritics Planet. Sci. 51, 1701-1720.

Eugster, O., Herzog, G.F., Marti, K., Caffee, M.W., 2006. Irradiation records, cosmic-ray exposure ages, and transfer times of meteorites, in Meteorites and the Early Solar System II, pp. 829-851.

Friedrich, J. M., Weisberg, M. K., Ebel, D. S., Biltz, A. E., Corbett, B. M., Iotzov, I. V., Khan, W. S., Wolman, M. D., 2015. Chondrule size and related physical properties: A compilation and evaluation of current data across all meteorite groups. Chemie der Erde $75,419-443$. 
Ganino, C., Libourel, G., 2017. Reduced and unstratified crust in CV chondrite parent body. Nature Communications 8, 261.

Gattacceca, J., Krzesinska, A.M., Marrocchi, Y., Meier, M.M., Bourot-Denise, M., Lenssen, R., 2017. Young asteroid mixing revealed in ordinary chondrites: the case of NWA 5764, a polymict LL breccia with L clasts. Meteoritics Planet. Sci. 52, 2289-2304.

Gattacceca, J., Rochette, P., Denise, M., Consolmagno, G., Folco, L., 2005. An impact origin for the foliation of ordinary chondrites. Earth Planet. Sci. Lett. 234, 351-368.

Gravnik, M., Brown, P., 2018. Identification of meteorite source regions in the Solar System. Icarus 311, 271-287.

Greenwood, R.C., Franchi, I.A., Kearsley, A.T., Alard, O., 2010. The relationship between CK and CV chondrites. Geochim. Cosmochim. Acta 74, 1684-1705.

Greenwood, R.C., Burbine, T.H., Miller, M.F., Franchi, I.A., 2017. Melting and differentiation of early-formed asteroids: The perspective from high precision oxygen isotope studies. Chemie der Erde - Geochemistry 77,1-43.

Greenwood, R.C., Burbine, T.H., Franchi, I.A., 2020. Linking asteroids and meteorites to the primordial planetesimal population. Geochim. Cosmochim. Acta, doi: https://doi.org/10.1016/j.gca.2020.02.004

Gröning, M., 2004. Chapter 40 - International Stable Isotope Reference Materials. In Handbook of Stable Isotope Analytical Techniques. pp. 874-906.

Holliday, I.E., 2017. Kolmogorov-Smirnov Test (v1.0.4) in Free Statistics Software (v1.2.1), Office for Research Development and Education, URL https://www.wessa.net/rwasp_Reddy-Moores\%20K-S\%20Test.wasp/

Howarth, R.J., 1998. Improved estimators of uncertainty in proportions, point-counting, and pass-fail test results. American J. Sci. 298, 594-607. 
474 Klein, P.P., 2012. On the ellipsoid and plane intersection equation. Applied Mathematics 3,

475

476

477

478

479

480

481

482

483

484

485

486

487

488

489

490

491

492

493

494

495

496

497

498 1634-1640.

Krot, A.N., Scott, E.R.D., Zolensky, M.E., 1995. Mineralogical and chemical modification of components in CV3 chondrites: Nebular or asteroidal processing? Meteoritics 30, 748775.

Krot, A.N., Petaev, M.I., Scott, E.R.D., Choi, B.-G., Zolensky, M.E., Keil, K., 1998. Progressive alteration in CV3 chondrites: More evidence for asteroidal alteration. Meteoritics Planet. Sci. 33, 1065-1085.

Krot, A.N., Meibom, A., Keil, K., 2000. A clast of Bali-like oxidized CV material in the reduced CV chondrite breccia Vigarano. Meteoritics Planet. Sci. 35, 817-825.

Lee, M.R., Cohen, B.E., King, A.J., Greenwood, R.C., 2019. The diversity of CM carbonaceous chondrite parent bodies explored using Lewis Cliff 85311. Geochim. Cosmochim. Acta 264, 224-244.

McSween, H.Y., 1977. Petrographic variations among carbonaceous chondrites of the Vigarano type. Geochim. Cosmochim. Acta 41, 1777-1790.

Mayeda, T.K., Clayton, R.N., 1998. Oxygen isotope effects in serpentine dehydration. Lunar Planet. Sci. Conf. 29, abstract \#1405.

Metzler, K., 2018. From 2D to 3D chondrule size data: Some empirical ground truths. Meteoritics Planet. Sci 53, 489-1499.

Nelson, V.E., Rubin, A., 2002. Size-frequency distributions of chondrules and chondrule fragments in LL3 chondrites: Implications for parent-body fragmentation of chondrules. Meteoritics Planet. Sci. 37, 1361-1376.

Rochette, P., Sagnotti, L., Bourot-Denise, M., Consolmagno, G., Folco, L., Gattacceca, J., Osete, M. L., Pesonen, L., 2003. Magnetic Classification of stony meteorites: 1. Ordinary chondrites. Meteoritics Planet. Sci. 38, 251-258. 
Rochette, P., Gattacceca, J., Bonal, L., Bourot-Denise, M., Chevrier, V., Clerc, J.-P., Consolmagno, G., Folco, L., Gounelle, M., Kohout, T., Pesonen, L., Quirico, E., Sagnotti, L., Skripnik, A., 2008. Magnetic Classification of Stony Meteorites: 2. NonOrdinary Chondrites. Meteoritics Planet. Sci. 43, 959-980.

Rubin, A. E., 1984. Coarse-grained chondrule rims in type 3 chondrites. Geochim. Cosmochim. Acta 48, 1779-1789.

Rubin, A. E. 2012. Collisional facilitation of aqueous alteration of CM and CV carbonaceous chondrites. Geochim. Cosmochim. Acta 90, 181-194.

Scherer, P., Schultz, L., 2000. Noble gas record, collisional history, and pairing of CV, CO, CK, and other carbonaceous chondrites. Meteorit. Planet. Sci. 35, 145-153.

Suavet, C., Alexandre, A., Franchi, I. A., Gattacceca, J., Sonzogni, C., Greenwood, R. C., Folco, L., Rochette, P., 2010. Identification of the parent bodies of micrometeorites with high-precision oxygen isotope ratios. Earth Planet. Sci. Lett. 293, 313-320.

Wasson, J. T., Isa, J., Rubin, A. E., 2013. Compositional and petrographic similarities of CV and CK chondrites: A single group with variations in textures and volatile concentrations attributable to impact heating, crushing and oxidation. Geochim. Cosmochim. Acta 108, 45-62.

Weisberg, M. K., McCoy, T. J., Krot, A. N., 2006. Systematics and evaluation of meteorite classification. In Meteorites and the Early Solar System II, edited by Lauretta, Dante S. and Sween Jr, H. Y., pp. 19-52.

Yin, Q.-Z., Sanborn, M.E., 2019. An update on disconnecting CV and CK chondrites parents bodies and more. 50th Lunar Planet. Sci. Conf., abstract \#3023. 


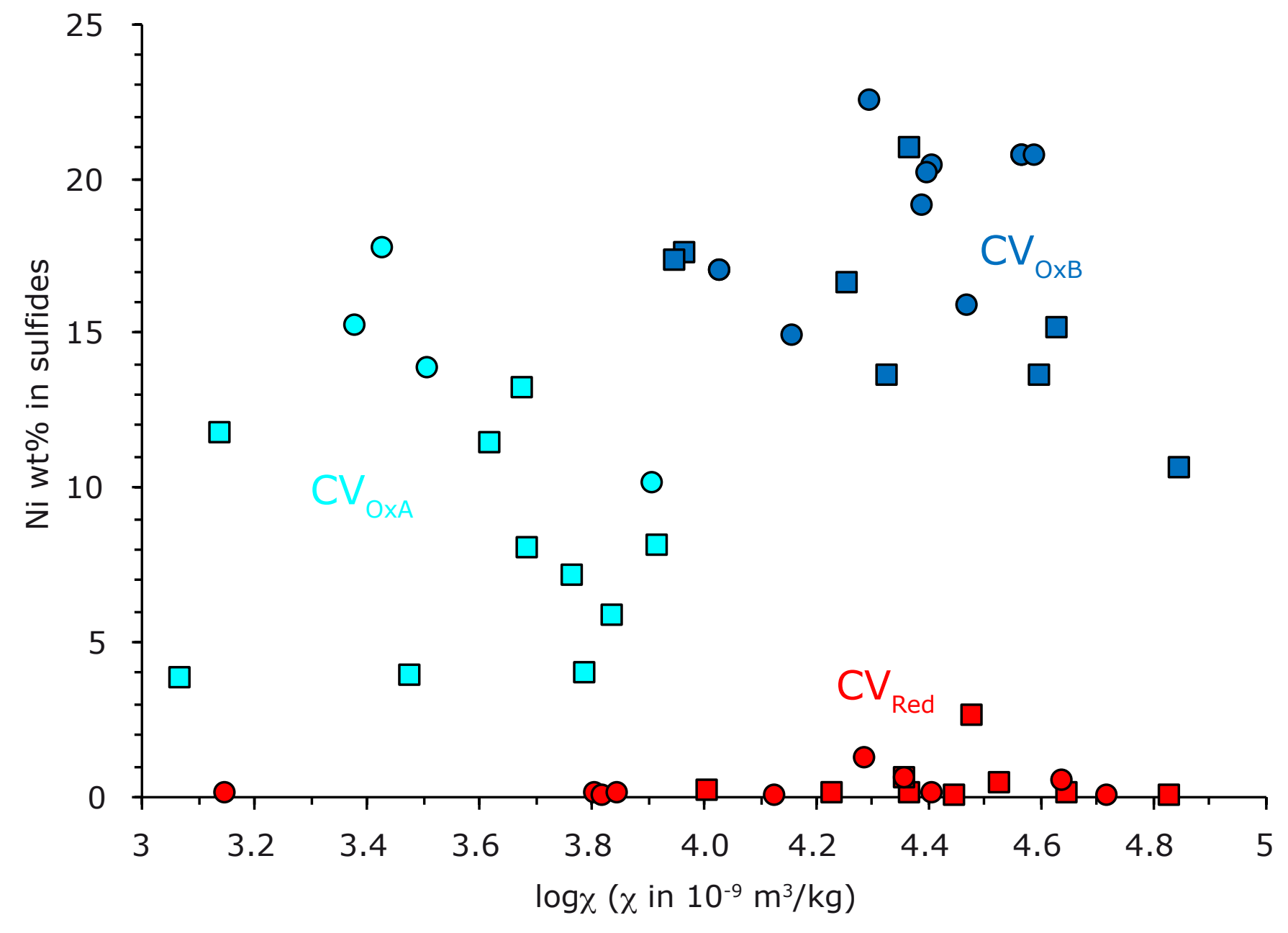


Figure 2

Click here to download Figure:1Fig2-cumulative plots.pdf
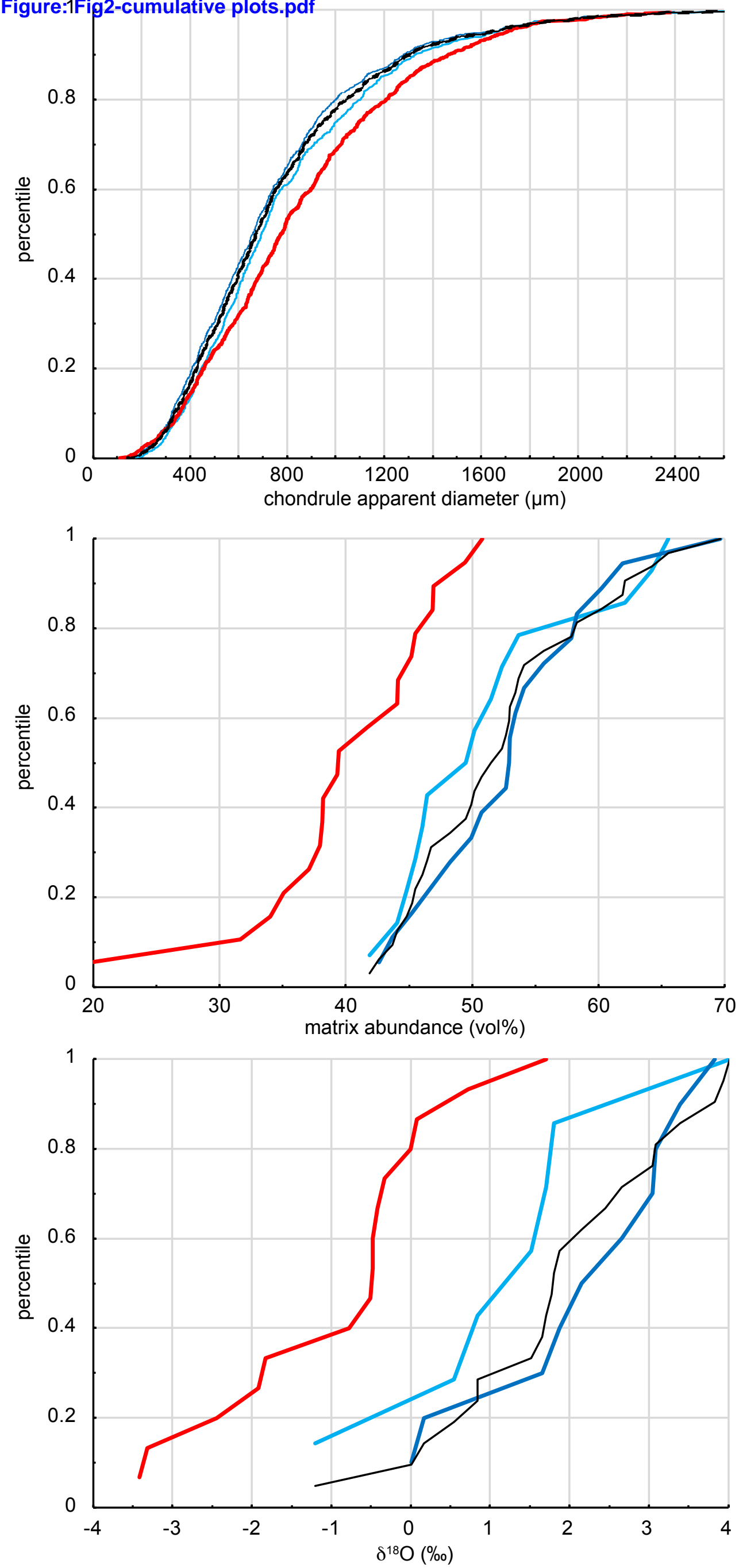


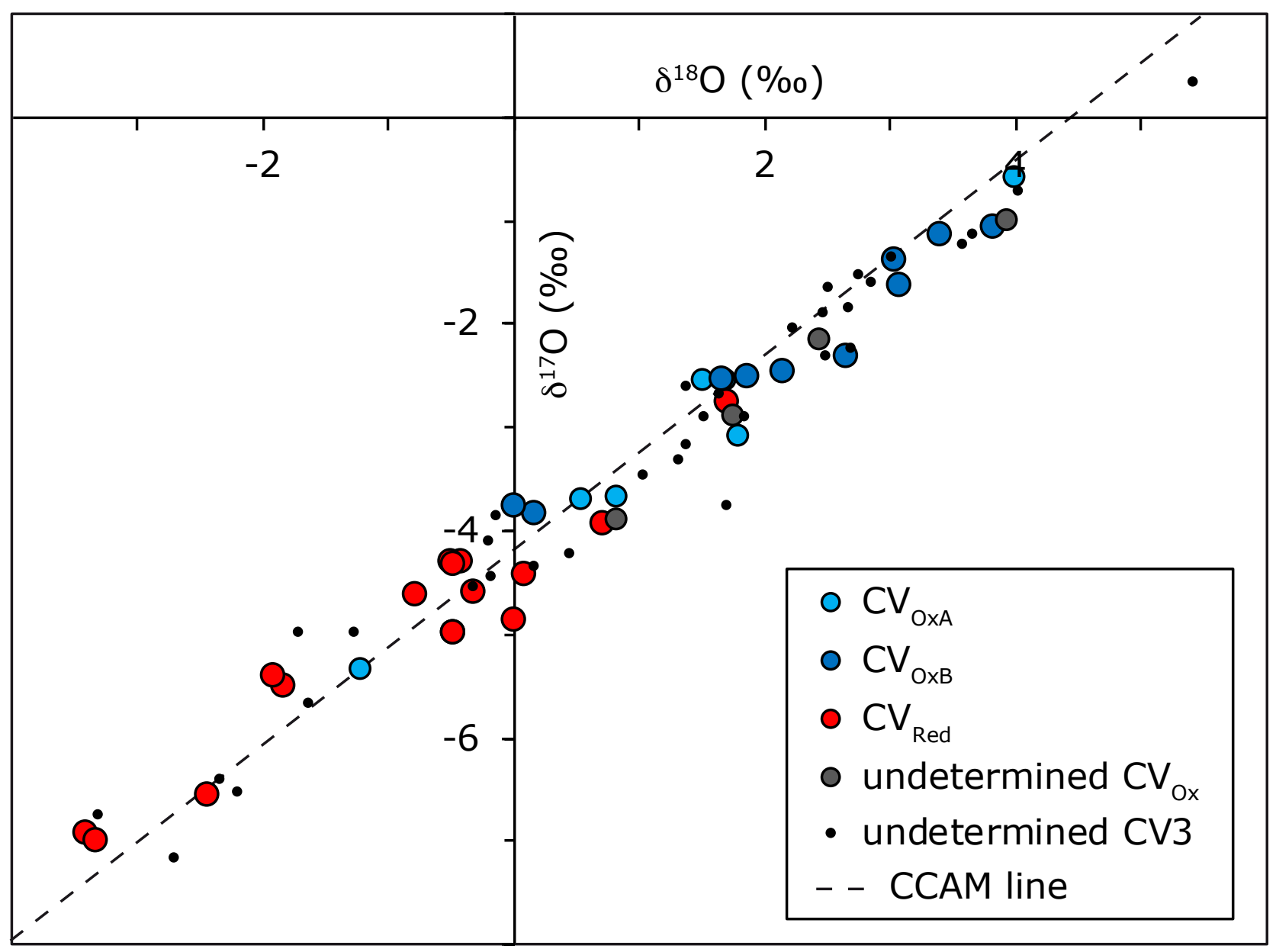


Click here to download high resolution image

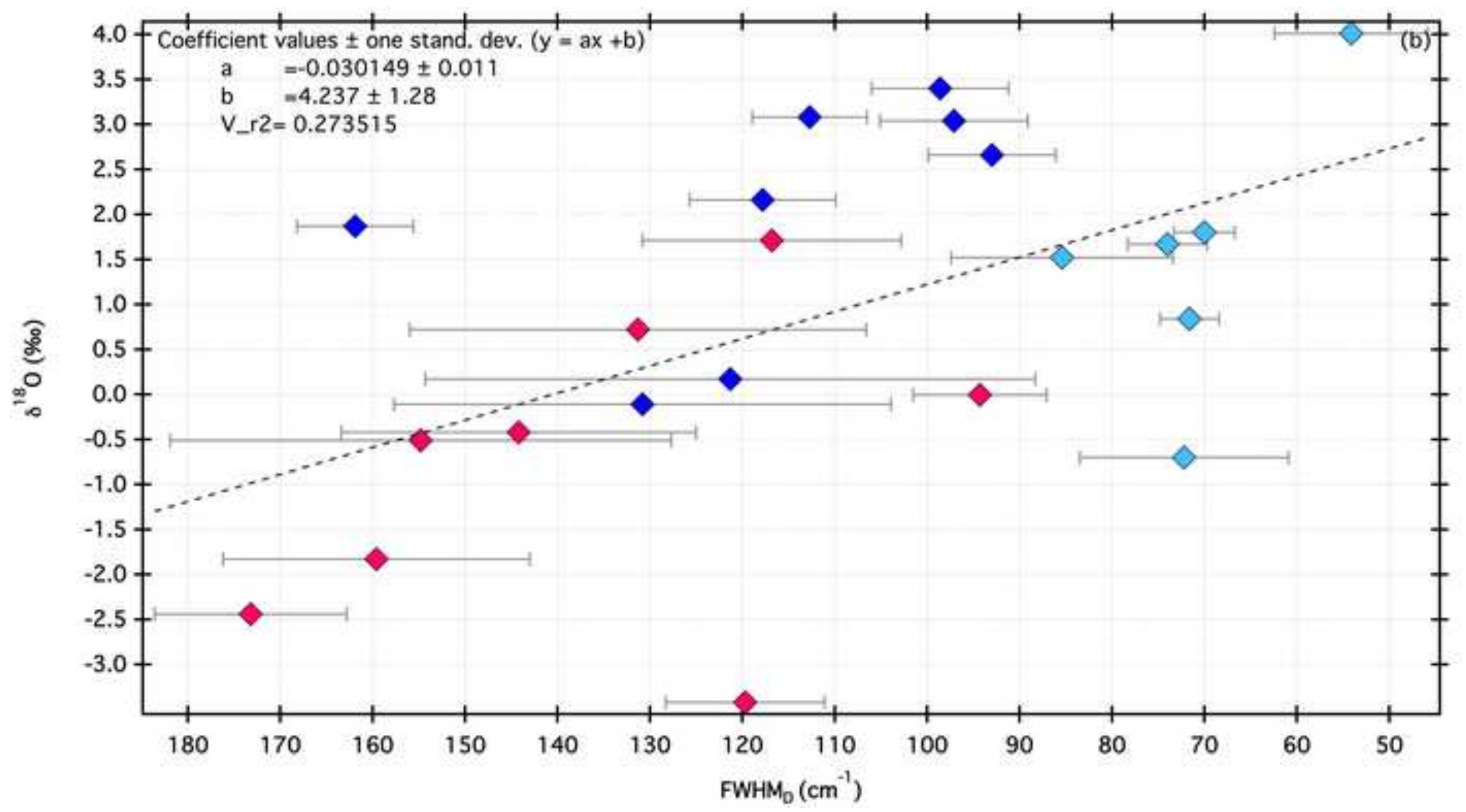


Click here to download high resolution image

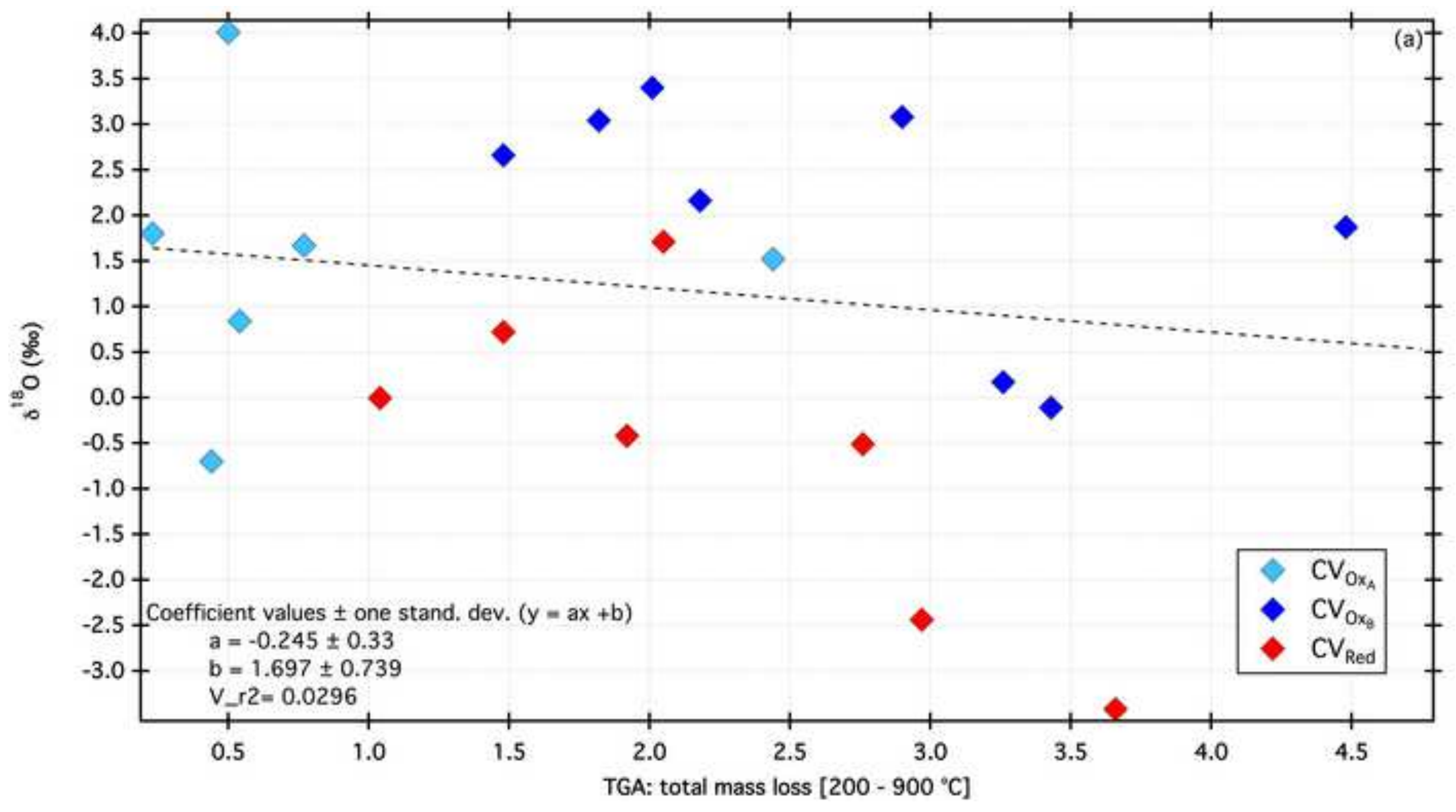


Click here to download Table: Table 1-CV properties.xIsx

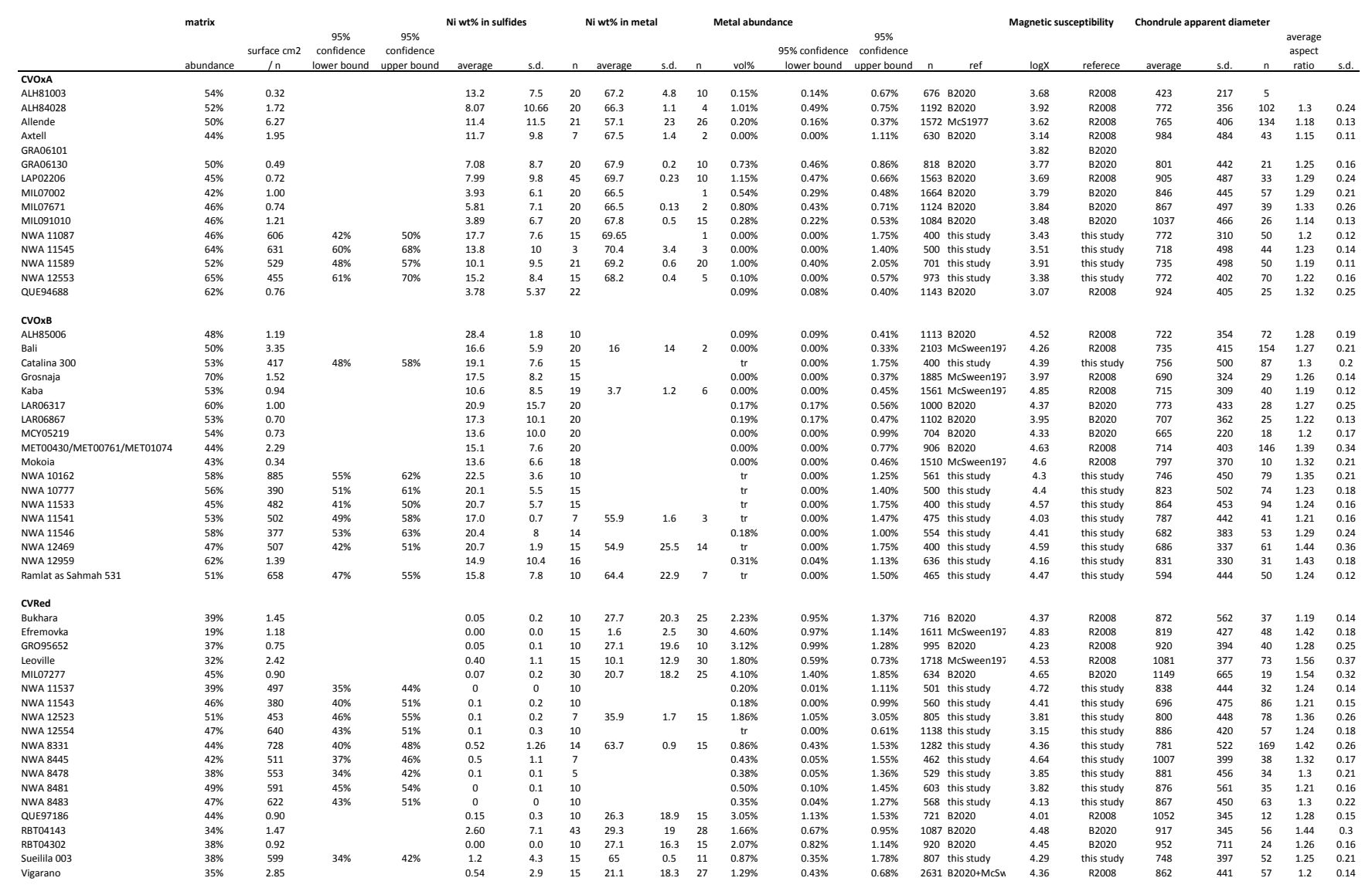


Click here to download Table: Table 5-oxygen isotopes summary with170.xlsx

\begin{tabular}{llllll} 
meteorite & $\mathbf{1 8 0}$ & $\mathbf{1 7 0}$ & $\mathbf{1 7 0}$ & $\mathrm{n}$ & \multicolumn{1}{c}{ Ref } \\
\hline CV3 OxA & & & & & \\
Allende & 1.71 & -2.56 & -3.45 & 4 & C\&M1999, G2010, this study \\
Axtell & 1.52 & -2.56 & -3.35 & 2 & C\&M1999, G2010, this study \\
ALH 84028 & 0.54 & -3.71 & -3.99 & 3 & C\&M1999, G2010, this study \\
ALH 81003 & 1.80 & -3.09 & -4.03 & 3 & G2010, this study \\
GRA 06101 & 0.84 & -3.69 & -4.13 & 1 & this study \\
LAP 02206 & 4.01 & -0.59 & -2.68 & 1 & this study \\
NWA 11589 & -1.20 & -5.36 & -4.73 & 1 & this study
\end{tabular}

\section{CV3 OxB}

Bali

$\begin{array}{lllll}3.40 & -1.13 & -2.89 & 2 & \mathrm{C} \& M 1999, \mathrm{G} 2010\end{array}$

ALH 85006

$\begin{array}{lllll}0.17 & -3.82 & -3.91 & 1 & \text { G2010 }\end{array}$

Grosnaja

$\begin{array}{lllll}3.08 & -1.62 & -3.22 & 1 & \mathrm{G} 2010\end{array}$

Kaba

$\begin{array}{lllll}1.87 & -2.50 & -3.47 & 1 & \mathrm{G} 2010\end{array}$

LAR 06317

$0.01-3.74 \quad-3.75 \quad 2$ this study

Mokoia

$\begin{array}{lllll}3.04 & -1.38 & -2.96 & 2 & \mathrm{C} \& M 1999, \mathrm{G} 2010\end{array}$

MCY 05219

$\begin{array}{lllll}2.66 & -2.31 & -3.70 & 1 & \text { this study }\end{array}$

MET 00761

$\begin{array}{lllll}2.16 & -2.45 & -3.57 & 1 & \text { this study }\end{array}$

NWA 11533

$\begin{array}{lllll}3.83 & -1.07 & -3.06 & 1 & \text { this study }\end{array}$

NWA 11546

$\begin{array}{lllll}1.66 & -2.52 & -3.38 & 1 & \text { this study }\end{array}$

\section{CV3 Ox}

FRO 97002

$2.45-2.16-3.43 \quad$ MDB

NWA 6746

$\begin{array}{lll}0.84 & -3.90 & -4.34\end{array}$

$M D B$

NWA 7110

$3.94-1.01-3.06$

MDB

Khawr al Fazra 005

$\begin{array}{lll}1.77 & -2.89 & -3.81\end{array}$

MDB

$\begin{array}{lccccl}\text { CV3 Red } & & & & & \\ \text { Arch } & 0.08 & -4.42 & -4.46 & 2 & \text { C\&M1999, G2010 } \\ \text { Bukhara } & 0.00 & -4.87 & -4.87 & 2 & \text { this study } \\ \text { Efremovka } & -1.83 & -5.51 & -4.55 & 2 & \text { C\&M1999, G2010 } \\ \text { GRO95652 } & -3.42 & -6.91 & -5.13 & 1 & \text { G2010 } \\ \text { Leoville } & -2.44 & -6.55 & -5.28 & 2 & \text { C\&M1999, G2010 } \\ \text { MIL 07277 } & 0.72 & -3.94 & -4.31 & 1 & \text { this study } \\ \text { NWA 8331 } & -0.78 & -4.60 & -4.20 & 4 & \text { MDB } \\ \text { NWA 12523 } & -0.33 & -4.60 & -4.43 & 1 & \text { this study } \\ \text { QUE 93429 } & -3.32 & -7.00 & -5.27 & 1 & \text { C\&M1999 } \\ \text { QUE 97186 } & 1.71 & -2.74 & -3.63 & 1 & \text { this study } \\ \text { RBT0 4143 } & -0.42 & -4.30 & -4.08 & 1 & \text { this study } \\ \text { RBT0 4302 } & -0.51 & -4.30 & -4.03 & 1 & \text { this study } \\ \text { DaG 1063 } & -0.48 & -4.32 & -4.07 & 1 & \text { MDB } \\ \text { NWA 2044 } & -1.92 & -5.41 & -4.41 & 2 & \text { MDB }\end{array}$


Click here to download Table: Table 4-oxygen isotopes CEREGE with170.xIsx

\begin{tabular}{|c|c|c|c|c|c|}
\hline meteorite & $180 \square$ & $170 \square$ & $170 \square$ & $\begin{array}{c}\text { initial sample } \\
\text { mass (mg) }\end{array}$ & $\mathbf{n}$ \\
\hline \multicolumn{6}{|l|}{ CVOxA } \\
\hline Allende & 1.828 & -2.650 & -3.601 & 84 & 1 \\
\hline ALH 84028 & 3.022 & -1.623 & -3.194 & 9 & 1 \\
\hline GRA 06101 & 0.841 & -3.692 & -4.129 & 52 & 1 \\
\hline LAP 02206 & 4.013 & -0.590 & -2.677 & 46 & 1 \\
\hline NWA11589 & 1.550 & -2.748 & -3.554 & 250 & 1 \\
\hline \multicolumn{6}{|l|}{ CVOxB } \\
\hline LAR 06317 & 0.010 & -3.743 & -3.748 & 50 & 2 \\
\hline MCY 05219 & 2.661 & -2.312 & -3.696 & 36 & 1 \\
\hline MET 00761 & 2.155 & -2.445 & -3.566 & 25 & 1 \\
\hline NWA 11533 & 3.830 & -1.065 & -3.057 & 161 & 1 \\
\hline NWA 11546 & 1.658 & -2.522 & -3.384 & 604 & 1 \\
\hline \multicolumn{6}{|l|}{ CVRed } \\
\hline Bukhara & -0.004 & -4.872 & -4.870 & 10 & 2 \\
\hline MIL 07277 & 0.720 & -3.937 & -4.311 & 69 & 1 \\
\hline NWA 8331 & -0.775 & -4.600 & -4.197 & 205 & 4 \\
\hline NWA 12523 & -0.326 & -4.595 & -4.425 & 256 & 1 \\
\hline QUE 97186 & 1.707 & -2.741 & -3.629 & 18 & 1 \\
\hline RBT 04143 & -0.421 & -4.295 & -4.076 & 20 & 1 \\
\hline RBT 04302 & -0.509 & -4.298 & -4.033 & 13 & 1 \\
\hline
\end{tabular}




$\begin{array}{lccc}\text { CVOx versus CVRed } & \text { n CVOx } & \text { n CVRed } & p \\ \text { matrix abundance } & 32 & 19 & 1.23 \mathrm{E}-04 \\ \delta 180 & 21 & 16 & 6.00 \mathrm{E}-05 \\ \text { chondrule diameter } & 1792 & 1015 & 6.78 \mathrm{E}-10 \\ & & & \\ \text { CVOxA versus CVOxB } & \mathrm{n} \text { CVOxA } & \mathrm{n} \text { CVOxB } & \mathrm{p} \\ \text { matrix abundance } & 14 & 18 & 2.95 \mathrm{E}-01 \\ \delta 180 & 7 & 10 & 1.17 \mathrm{E}-01 \\ \text { chondrule diameter } & 706 & 1086 & 5.60 \mathrm{E}-02\end{array}$


Table 2

Click here to download Table: Table 2-CV average properties.pdf

\begin{tabular}{|c|c|c|c|c|c|c|c|c|c|c|c|c|c|c|c|c|c|}
\hline & \multicolumn{2}{|c|}{ matrix abundance } & \multicolumn{3}{|c|}{$\mathrm{Ni}$ content in sulfides } & \multicolumn{3}{|c|}{ Metal abundance } & \multicolumn{3}{|c|}{ Magnetic susceptibility } & \multicolumn{4}{|c|}{ Chondrule apparent diameter } & \multicolumn{2}{|c|}{ hondrule aspect ratio } \\
\hline & vol\% & sd & $\mathrm{n}$ & $w t \%$ & s.d. & $\mathrm{n}$ & vol\% & sd & $\mathrm{n}$ & $\log X$ & sd & $\mathrm{n}$ & $\mu \mathrm{m}$ & s.d. & $\mathrm{n}$ & average & s.d. \\
\hline CVOXA & $51,3 \%$ & $7,4 \%$ & 14 & 9,55 & 4,31 & 14 & 0,43 & 0,41 & 14 & 3,60 & 0,26 & 15 & 796 & 426 & 705 & 1,225 & 0,062 \\
\hline CVOxB & $53,2 \%$ & $6,7 \%$ & 18 & 18,04 & 3,96 & 18 & 0,09 & 0,11 & 11 & 4,38 & 0,23 & 18 & 749 & 427 & 1086 & 1,296 & 0,073 \\
\hline CVOx & $52,3 \%$ & $7,0 \%$ & 32 & 14,32 & 5,89 & 32 & 0,28 & 0,36 & 25 & 4,03 & 0,46 & 33 & 768 & 428 & 1791 & 1,265 & 0,062 \\
\hline CVRed & $40,3 \%$ & $7,1 \%$ & 19 & 0,34 & 0,61 & 19 & 1,64 & 1,32 & 18 & 4,27 & 0,39 & 19 & 860 & 477 & 1015 & 1,332 & 0,066 \\
\hline
\end{tabular}



Figure S1
Click here

Click here to download Supplementary material for online publication only: Figure S1-elipsoids flattening.pdf Clit 